\title{
The Extension Evaluation Theory Based on Wind Power Project Quality
}

\author{
Yang Maosheng,Zhang Haijian \\ Xi'an University of Architecture and Technology. \\ Xi'an ,China \\ e-mail:244591882@qq.com
}

\begin{abstract}
According to basic characteristics of wind power project,using the extension theory and extension model,to establish a set of government project department for evaluation of wind power project quality evaluation index system. The weight values of each index and the correlation matrix, Through the correlation matrix and a series of index multiplication,get A comprehensive numerical. According to the classification index grade before setting the region, The wind power project quality grade. the area for wind power project quality and the level of evaluation, and reflects a quality level for evaluation of wind power project in the selection of sample, adjustment and improvement in order to help the government departments or enterprises for wind power project investment and management for better. Prior to the start of the project, The assessment of the project, from the aspects of reducing losses.Other,Improvement from the aspects to be improved. In order to improve the quality of wind power project to improve.In order to improve the comprehensive quality of wind power goal.
\end{abstract}

Keywords-wind power project; extension theory; quality evaluation; evaluation model;correlation matrix

\section{I . INTRODUCTION}

Wind energy is an inexhaustible, green environmental protection renewable resources to replace part of the primary energy, more importantly, does not emit any harmful gases ${ }^{[1]}$. It can reduce carbon dioxide, nitrogen oxides and other harmful gas emissions and help protect the environment. For a long time, quantitative and comprehensive evaluation of wind power project has always been the goal of wind power project workers to work hard ${ }^{[2]}$. Currently, the core of a comprehensive evaluation of the quality of wind power projects is how a multi-index is scientifically, objectively and reasonably transformed into a single quantitative indicator of problems. So far, many scholars' comprehensive evaluation of wind power projects were discussed, and a comprehensive evaluation of wind power projects further complement and optimization. Most of the current evaluation methods were based on fuzzy evaluation method $^{[3]}$. The core of the fuzzy evaluation method is how to evaluate the relationship between the amount to be used with the evaluation interval fuzzy method to quantify, but if the assessment and evaluation of membership are similar, it is difficult to determine the ownership of interval. Based on this situation, we are using extension analysis method of matter element and correlation function concept, to quantify the amount of generation and evaluation interval to associate value matrix. And according to different projects for different sensitive degree of different indicators to the quality of wind power project, to determine the weights of indexes and calculate the result by using entropy method. Through qualitative and quantitative evaluation of wind power project ${ }^{[4]}$, the new method can make the evaluation results more objective, accurate, reasonable.

\section{II . BUILD THE QUALITY EVALUATION SYSTEM OF WIND POWER PROJECT}

\section{A. Build the quality evaluation system of wind power project}

In building wind power project quality evaluation system, not only be considered the basic characteristics of the project, but also the government's macro guidance, difficulty of information collection and high complexity. Considering these factors with scientificity, practicability, 
comprehensive, systematicness, generality, comparability, and combination of qualitative and quantitative analysis of evaluation system, ${ }^{[5]}$ referring, mainly from project orientation, project influence, project benefits, finance and tax contribution, the investment intensity and the comprehensive drive six aspects, the quality evaluation system of Shaanxi province key industry project ${ }^{[6]}$, and investigation of experts and leadings.

\section{B. B. Determine the index weight}

Because of the Indicators of quality comprehensive performance evaluation system of wind power project have different influence to evaluation of overall goal, weight will have a decisive influence to the result of the project quality evaluation. So this article uses the entropy weight method to determine the index weight ${ }^{[7]}$. Through the way of questionnaire survey, inviting relevant experts and leadings to judge the significance among the indicators to get the judgment matrix, combining with chromatography analysis ${ }^{[8]}$, calculating and trade-offs, and consistency check, the weight of the indicators would be got finally.

\section{CONSTRUCTS THE EXTENSION MODEL OF THE}

\section{QUALITY EVALUATION OF WIND POWER PROJECT}

\section{A. Determine the measuring condition set}

According to the theory of matter element ${ }^{[9]}$, quality evaluation of wind power project first need to analysis various factors involved, according to the extension definition learned primitives and the establishment of wind power project quality evaluation index system, the quality of wind power project can be used by the following n-dimensional element to describe.

$$
R=(N, c, V)=\left[\begin{array}{ccc}
N, & \mathrm{c}_{1}, & \mathrm{v}_{1} \\
& \mathrm{c}_{2}, & \mathrm{v}_{2} \\
\vdots & \vdots \\
& c_{i}, & v_{i}
\end{array}\right]
$$

Among them, $\mathrm{N}$ stands for the quality of wind power project to evaluate ; $c_{i}(j=1,2, \ldots, n)$ represents factors affecting quality evaluation of wind power project, that is evaluation index; Vi indicates the range value of industry $\mathrm{N}$ about index $c_{i}$.

\section{B. Determine the Classical domain}

If we divide the effec tevaluation degree of each index into $\mathrm{J}$ ranks, classical matter-element matrix is :

$$
R_{o j}=\left(N_{o j}, c, V\right)=\left[\begin{array}{ccc}
N_{o j}, & c_{1}, & \mathrm{~V}_{o j 1} \\
& c_{2}, & \mathrm{~V}_{0 j 2} \\
\vdots & \vdots \\
& c_{i}, & V_{0 j i}
\end{array}\right]=\left[\begin{array}{ccc}
N_{o j}, & c_{1}, & \left\langle a_{o j 1}, b_{o j 1}\right\rangle \\
& c_{2}, & \left\langle a_{o j 2}, b_{o j 2}\right\rangle \\
\vdots & \vdots \\
& c_{i}, & \left\langle a_{o j i}, b_{o j i}\right\rangle
\end{array}\right]
$$

Above,Noj is the $\mathrm{j}$ level, $\mathrm{CI}$ is the $\mathrm{I}(\mathrm{i}=1,2, \ldots \mathrm{N})$, evaluation indexes, as classical field corresponds to the Noj of each evaluation index.

\section{To determine the day domain}

The matter-element $R_{p}$ quality evaluation of wind power project is:

$$
R_{p}=\left(N_{p}, c, V_{p i}\right)=\left[\begin{array}{ccc}
N_{p}, & c_{1}, & v_{p 1} \\
& c_{2}, & v_{p 2} \\
\vdots & \vdots \\
c_{i}, & v_{p i}
\end{array}\right]=\left[\begin{array}{ccc}
N_{p}, & c_{1}, & \left\langle a_{p 1}, b_{p 1}\right\rangle \\
& c_{2}, & \left\langle a_{p 2}, b_{p 2}\right\rangle \\
\vdots & \vdots \\
& c_{i}, & \left\langle a_{p i}, b_{p i}\right\rangle
\end{array}\right] \text { (3) }
$$

Among them, CI $(\mathrm{i}=1,2, \ldots \mathrm{N})$ is influencing factors of quality of wind power project, namely evaluation index; all values of $V_{p i}$ is the evaluation index of $\mathrm{C}$, namely the joint domain. $\left\langle a_{p i}, b_{p i}\right\rangle(i=1,2, \cdots, n)$

\section{To determine the matter element evaluation}

Present the evaluating wind power project quality factors corresponding data by using matter element.

$$
R=(N, c, V)=\left[\begin{array}{ccc}
N, & \mathrm{c}_{1}, & \mathrm{v}_{1} \\
& \mathrm{c}_{2}, & \mathrm{v}_{2} \\
& \vdots & \vdots \\
& c_{i}, & v_{i}
\end{array}\right]
$$

$\mathrm{N}$ stands for evaluation quality of wind power project; $\mathrm{V}$ is measured data actually for evaluation of wind power project corresponding to the index C. 


\section{E. Calculate the related value matrix}

Use the correlation function to describe some degree of the domain . The basic formula of correlation function in real field extension set is established, the process so that it can quantitatively, objectively describe some properties of the degree and the process of quantitative change .

\section{$F$. The determination of the comprehensive evaluation grade}

According to the assessment requirements wind power project quality, after count the weights of wind power project quality evaluation indexes, results can be got according to the following formula:

$$
P=W \square F
$$

In the above formula, F stands for the correlation matrix.

\section{EMPIRICAL ANALYSIS}

Based on wind power project quality evaluation system, select one wind power project as the research object, and carries out the extension evaluation, so as to determine the quality grade of wind power project to be evaluated.

\section{A. Dividing the evaluation standard}

Through the statistical and analysis of the data of 53 wind power projects, invite relevant experts to analysis the evaluation indexes of wind power project according to work experience, then confirm the interval of each evaluation index e.

\section{B. Determine matter-element of extensible evaluation}

According to quality evaluation scale of wind power project, it determines, in each level, the matter-elements of classical fields and note fields, and those would be evaluated, which are showed as follow.

\begin{tabular}{|c|c|c|c|c|c|c|}
\hline \multirow{19}{*}{$R_{\mathrm{O}}=$} & \multirow{19}{*}{$\begin{array}{l}c_{1} \\
c_{2} \\
c_{3} \\
c_{4} \\
c_{5} \\
c_{6} \\
c_{7} \\
c_{8} \\
c_{9} \\
c_{10} \\
c_{11} \\
c_{12} \\
c_{13} \\
c_{14} \\
c_{15} \\
c_{16} \\
c_{17} \\
c_{18} \\
c_{19}\end{array}$} & $\begin{array}{c}N_{01} \\
(0,1 \%)\end{array}$ & $\begin{array}{c}N_{02} \\
(1 \%, 3 \%)\end{array}$ & $\begin{array}{c}N_{03} \\
(3 \%, 5 \%)\end{array}$ & $\begin{array}{c}N_{04} \\
(5 \%, 7 \%)\end{array}$ & $\begin{array}{c}N_{05} \\
(7 \%, 10 \%)\end{array}$ \\
\hline & & $(0,0.002)$ & $(0.002,0.0066)$ & $(0.0066,0.013)$ & $(0.013,0.0367)$ & $(0.0367,0.095)$ \\
\hline & & $(0,0.55)$ & $(0.55,0.68)$ & $(0.68,0.77)$ & $(0.77,0.87)$ & $(0.87,0.93)$ \\
\hline & & $(0,3.4 \%)$ & $(3.4 \%, 4.8 \%)$ & $(4.8 \%, 6.1 \%)$ & $(6.1 \%, 7.6 \%)$ & $(7.6 \%, 8.2 \%)$ \\
\hline & & $(0,0.0001)$ & $(0.0001,0.0005)$ & $(0.0005,0.0083)$ & $(0.0083,0.011)$ & $(0.011,0.0122)$ \\
\hline & & $(0,1.2 \%)$ & $(1.2 \%, 2.3 \%)$ & $(2.3 \%, 3.7 \%)$ & $(3.7 \%, 4.8 \%)$ & $(4.8 \%, 5.7 \%)$ \\
\hline & & $(0,1.4 \%)$ & $(1.4 \%, 2.5 \%)$ & $(2.5 \%, 3.6 \%)$ & $(3.6 \%, 4.7 \%)$ & $(4.7 \%, 5.6 \%)$ \\
\hline & & $(0,1.1 \%)$ & $(1.1 \%, 2.3 \%)$ & $(2.3 \%, 3.5 \%)$ & $(3.5 \%, 4.3 \%)$ & $(4.3 \%, 5.4 \%)$ \\
\hline & & $(0,7.67 \%)$ & $(7.67 \%, 8.15 \%)$ & $(8.15 \%, 9.16 \%)$ & $(9.16 \%, 9.87 \%)$ & $(9.87 \%, 10.53 \%)$ \\
\hline & & $(0,7.06 \%)$ & $(7.06 \%, 8.55 \%)$ & $(8.55 \%, 9.52 \%)$ & $(9.52 \%, 13.13 \%)$ & $(13.13 \%, 15.52 \%)$ \\
\hline & & $(0,0.0037)$ & $(0.0037,0.1383)$ & $(0.1383,0.2268)$ & $(0.2268,0.4893)$ & $(0.4893,1.173)$ \\
\hline & & $(0,0.251)$ & $(0.251,0.547)$ & $(0.547,0.736)$ & $(0.736,0.778)$ & $(0.778,0.841)$ \\
\hline & & $(0,36.355)$ & $(36.355,87.273)$ & $(87.273,151.9)$ & $(151.9,494.58)$ & $(494.58,705.36)$ \\
\hline & & $(0,5.721)$ & $(5.721,15.98)$ & $(15.98,21.83)$ & $(21.83,33.27)$ & $(33.27,41.26)$ \\
\hline & & $(0,134.43)$ & $(134.43,193.38)$ & $(193.38,237.4)$ & $(237.4,261.8)$ & $(261.8,402.3)$ \\
\hline & & $(0,0.815)$ & $(0.815,0.93)$ & $(0.93,0.956)$ & $(0.956,0.972)$ & $(0.972,0.977)$ \\
\hline & & $(0,1.3 \%)$ & $(1.3 \%, 2.3 \%)$ & $(2.3 \%, 3.5 \%)$ & $(3.5 \%, 4.6 \%)$ & $(4.6 \%, 5.5 \%)$ \\
\hline & & $(0,1.2 \%)$ & $(1.2 \%, 2.2 \%)$ & $(2.2 \%, 3.1 \%)$ & $(3.1 \%, 4.3 \%)$ & $(4.3 \%, 5.4 \%)$ \\
\hline & & $(0,51.43)$ & $(51.43,126.36)$ & $(126.36,177)$ & $(177,204.53)$ & $(204.53,279.36)$ \\
\hline
\end{tabular}




$$
R_{p}=\left[\begin{array}{ccc}
N & c_{1} & (0,10 \%) \\
& c_{2} & (0,0.095) \\
c_{3} & (0,0.93) \\
c_{4} & (0,8.2 \%) \\
c_{5} & (0,0.0122) \\
c_{6} & (0,5.7 \%) \\
c_{7} & (0,5.6 \%) \\
c_{8} & (0,5.4 \%) \\
c_{9} & (0,10.53 \%) \\
c_{10} & (0,15.52 \%) \\
c_{11} & (0,1.173) \\
c_{12} & (0,0.841) \\
c_{13} & (0,705.36) \\
c_{14} & (0,41.26) \\
c_{15} & (0,402.3) \\
c_{16} & (0,0.977) \\
c_{17} & (0,5.5 \%) \\
c_{18} & (0,5.4 \%) \\
c_{19} & (0,279.36)
\end{array}\right] R=\left[\begin{array}{ccc}
N_{0} & c_{1} & 4.8 \% \\
c_{2} & 0.005 \\
c_{3} & 0.6 \\
c_{4} & 5 \% \\
c_{5} & 0.001 \\
c_{6} & 206 \\
c_{7} & 2.8 \% \\
c_{8} & 2.1 \% \\
c_{9} & 8.206 \\
c_{10} & 8.20 \\
c_{11} & 0.15 \\
c_{12} & 0.55 \\
c_{13} & 95.5 \\
c_{14} & 17.25 \\
c_{15} & 195.5 \\
c_{16} & 0.950 \\
c_{17} & 3.4 \% \\
c_{18} & 2.6 \% \\
c_{19} & 145.5
\end{array}\right]
$$

\section{Calculate the associated values of each evaluation} grade of the indicators and quality grade matter-elements to be evaluated.

Associated values of each evaluation grade of the indicators are computed.

$$
F=\left[\begin{array}{ccccc}
-0.4419 & -0.2727 & 0.0435 & -0.04 & -0.3143 \\
-0.375 & 0.4706 & -0.2424 & -0.6154 & -0.8638 \\
-0.1316 & 0.1786 & -0.1951 & -0.34 & -0.45 \\
-0.3333 & -0.0588 & 0.0667 & -0.2558 & -0.4483 \\
-0.4737 & -0.3333 & 1 & -0.8795 & -0.9091 \\
-0.2857 & 0.1765 & -0.1304 & -0.4595 & -0.5833 \\
-0.3333 & -0.0968 & 0.12 & -0.2222 & -0.4043 \\
-0.3226 & 0.1053 & -0.0870 & -0.4 & -0.5116 \\
-0.1853 & -0.0210 & 0.0219 & -0.2918 & -0.4175 \\
-0.1348 & 0.1133 & -0.0456 & -0.1528 & -0.4024 \\
-0.4938 & -0.0724 & 0.0846 & -0.3386 & -0.6934 \\
-0.5068 & -0.0102 & 0.0104 & -0.3899 & -0.4393 \\
-0.3825 & -0.0793 & 0.0943 & -0.3713 & -0.8069 \\
-0.4006 & -0.0686 & 0.0795 & -0.2098 & -0.4815 \\
-0.2380 & -0.0107 & 0.0110 & -0.1765 & -0.2532 \\
-0.8333 & -0.4255 & 0.2857 & -0.1818 & -0.4490 \\
-0.5 & -0.3438 & 0.05 & -0.0455 & -0.3636 \\
-0.35 & -0.1333 & 0.1818 & -0.1613 & -0.3953 \\
-0.4127 & -0.1251 & 0.1668 & -0.1905 & -0.3060
\end{array}\right]
$$

$P=W \sqcap F=(-0.3601, \quad-0.0076, \quad 0.0809, \quad-0.3883,-0.5680)$

, which shows the quality of wind power project is moderate.

\section{CONCLUSION}

Applying extension theory, a feasible evaluation method is presented to review the wind power project for the Government. Things are judged, according to the characteristic value, to belong to a certain set, which meets the principle of extension set. So it is objective and reasonable to research the wind power quality comprehensive evaluation with extenics matter-element theory.

According to the characteristics that correlation function fetches negative, the evaluation results of the quality of wind power projects could be more refined by using entropy weight method[10].

\section{REFERENCES}

[1] Zhang xiliang.Development and utilization of wind energy[M].Chemical Industry Press.2006(1):105 112

[2] Zhang guowei,Gong guangcai.Present situation and Prospect of wind energy utilization [J].Energy saving technology,2007, 25(1):71 76.

[3] Feng shenghong,Zhou xinquan,Xu jingde.Study on synthesis technology.Multi index comprehensive evaluation based on fuzzy integral theory. System engineering theory.Theory and Practice.1999(4):70 73.

[4] Chen Xiaoyan. Research on comprehensive evaluation of social benefits of wind power project[D]. Southwest petroleum university. 2012:18-19

[5] Ba yinhu.Study on evaluation of long yuan wind power projects[M].2011;10 25.

[6] Shanxi province development and reform commission Compilation(a) of Shaanxi province to promote the construction of key projects[G]. 2013:32 33

[7] Yan Wenzhou. The evaluation system of green building part[M] Xi'an: shaanxi science and technology publishing house, 2009:41-47

[8] Wang chunzhi,Si qin.Research and application of statistics in the treatment ofDelphy $\mathrm{Fa}[\mathrm{J}]$.Journal of Inner Mongolia Finance and Economics College(Comprehensive Edition).2011,(4) ; 92 96.

[9] Yang Chunyan, Cai Wen. Research on extension engineering[J]. China engineering, 2000,2(12): 90-96

[10] Xiao ming,Zhao hongwei,Wang xiaofeng.Study on the method of weight determined by entropy[J].Market modernization.2007,21 22 